\title{
La enseñanza jesuita en Chile colonial: sus colegios, universidades y una aproximación a sus métodos y contenidos
}

\author{
Alejandra Contreras Gutiérrez ${ }^{1}$ \\ Universidad de Santiago de Chile (Chile) \\ acongu80@gmail.com
}

Recepción: 30/09/2013

Evaluación: 18/10/2013

Aceptación: 13/12/2013

Artículo de Reflexión

DOI: http:/ / dx.doi.org/ 10.9757/Rhela.22/02

\section{RESUMEN}

El documento que se presenta a continuación tiene como objetivo informar sobre el aporte que hizo la Compañía de Jesús a la educación en Chile colonial, se proporcionará información de sus colegios, universidades, planes y métodos de estudios.

La idea con esta exposición es establecer que, con la llegada de los jesuitas al país y con el inicio de las labores educativas, se instala en Chile, por primera vez, un sistema de enseñanza. La metodología que hemos empleado para este trabajo consiste en la revisión y recopilación de datos provenientes de diversos textos que son considerados clásicos en la materia, así como también de historias de la propia orden en el país, de manera que se pueda reunir toda la información que se necesita para reconstruir el panorama general de la educación jesuita en Chile. Como este tema ha sido escasamente abordado por la historiografía contemporánea nacional, este trabajo pretende ser un aporte a la historia de la educación en Chile y en América Latina, en el sentido en que la experiencia educativa jesuita en Chile fue similar a la que se experimentó en otras naciones del continente.

Palabras clave: Revista Historia de la Educación Latinoamericana, Jesuitas, sistema de enseñanza y métodos de estudios.

\footnotetext{
1 Doctora en Estudios Americanos de la Universidad de Santiago de Chile, especialidad Pensamiento y Cultura. Becaria CONICYT para realizar estudios de postgrado. Profesora de Castellano y Magíster en Literatura Latinoamericana y Chilena por la Universidad de Santiago de Chile. Ha participado en proyecto de investigación FONDECYT (2006-2008), relacionado con el estudio del movimiento ilustrado en Hispanoamérica. Actualmente se encuentra desarrollando su tesis doctoral que versa sobre la Ilustración y el Enciclopedismo en Chile y el área andina.
} 
Its schools, universities, and an approach to its methods and contents
Jesuit teaching in colonial Chile:

A educação jesuítica no Chile colonial: Seus colégios, universidades e uma aproximação de seus métodos e conteúdos

\section{RESUMO}

The document below, aims at reporting on the contribution made by the Company of Jesus to the education in colonial Chile. It provides information about its schools, universities, plans and educational methods.

Our idea with this paper, is to establish that with the arrival of the Jesuits to the country and with the starting of the educational work, for the first time the system of education was established in Cali. The methodology used for this work, consists in the revision and collection of data from several texts that are considered classics in the field, as well as, stories of its own order in the country. In such a way as to be able to gather all the information we need to rebuild the overview of the Jesuit education in Chile. As this topic has been so poorly addressed by the national contemporary historiography, our work is intended to make a contribution to the history of education in Chile and Latin America, in the sense that the Jesuit educational experience in Chile, was similar to that experienced in other nations of the continent.

Key words: Journal History of the Latin American Education, Jesuits, education system and methods of studies.
O documento que apresentamos a seguir tem como objetivo informar sobre as contribuições da Companhia de Jesus à educação no Chile colonial, proporcionando informações sobre seus colégios, universidades, planos e métodos de estudos. Nosso objetivo com esta exposição é defender a ideia de que, com a chegada dos jesuítas ao país e com o início de sua obra educativa, instalou-se no Chile, pela primeira vez, um sistema de educação. A metodologia que empregamos para este trabalho consiste na revisão e reorganização de dados provenientes de diversos textos que são considerados clássicos na matéria, assim como de histórias da própria ordem no país, de maneira a poder reunir toda a informação que necessitamos para reconstruir o panorama geral da educação jesuíta no Chile. Como este tema foi tão pouco abordado pela historiografia contemporânea nacional, nosso trabalho pretende ser uma contribuição à história da educação no Chile e Latino-americana, no sentido de que a experiência educativa jesuítica no Chile foi similar ao que se experimentou em outras nações do continente.

Palavras-chave: Revista História da Educação Latino-americana, Jesuítas, sistema de educação e métodos de estudos.

\section{INTRODUCCIÓN}

El origen de la sociedad chilena estuvo marcado por una serie de dificultades que impidieron el normal desarrollo de una instrucción pública para sus habitantes. A la pobreza del Cabildo, que fue incapaz de costear un profesor de primeras letras, se sumó la Guerra de Arauco y los terremotos que, de tanto en tanto, consumían la atención y las fuerzas de los gobernantes. En este contexto, la llegada de la Compañía de Jesús al país fue una efectiva solución al problema, por cuanto esta desarrolló con éxito la labor educativa. 
Aunque antes de la llegada de los jesuitas a Chile, existían actividades educativas que fueron fomentadas por otras órdenes religiosas y por algunos particulares, se puede decir que estas actividades fueron aisladas y que nunca llegaron a constituirse en un sistema general de enseñanza. En cambio, la educación jesuítica, por las características que presenta, sí da cuenta de una organización que permite lucubrar sobre el hecho de que con su implementación se habría instalado por primera vez un sistema de enseñanza en Chile.

¿Cuáles eran las características de esta enseñanza?, ¿qué perseguía?, ¿cuáles fueron los colegios que los jesuitas tuvieron en Chile?, son algunas de las preguntas que intentaremos resolver en este trabajo, con el objeto de presentar un perfil de esta educación y de establecer su valor como iniciadora de un sistema de enseñanza en el país.

Dado que el estudio de la educación chilena colonial ha sido poco abordado, este trabajo pretende ser un aporte a la historia de la enseñanza en Chile y América Latina.

\section{Comienzos}

Los jesuitas llegaron desde Perú a Santiago de Chile el día 12 de abril de 1593, dirigidos por el provincial Baltasar de Piñas. A su llegada, tuvieron que permanecer transitoriamente en el Convento de Santo Domingo, hasta que las generosas donaciones hechas por los habitantes de la comunidad les permitieron adquirir una propiedad en donde se establecieron definitivamente.

Aunque la función principal que debían cumplir los jesuitas en Chile era la de contribuir con la evangelización de los indígenas y esclavos, lo cierto es que no tardaron en hacerse cargo de otro de los ministerios en que destacaban enormemente en las otras provincias, nos referimos, por supuesto, al de la instrucción.

Según Francisco Enrich en su Historia de la Compañia de Jesús en Chile de 1891, hacia 1593 no existían en el territorio centros de instrucción pública en donde 
se pudiesen educar a los niños en primeras letras ${ }^{2} \mathrm{y}$, menos aún, seminarios eclesiásticos en donde se enseñasen las ciencias mayores a los jóvenes que optaban por una vida al servicio de la religión. ${ }^{3}$ Este hecho, sumado al de la escasez que había en el país de misioneros que predicaran el evangelio a lo largo de la extensa y disipada población indígena, habría propiciado que el gobierno y los religiosos de otras órdenes que habitaban en Chile, y que eran concientes de la eficacia con que la Compañía desempañaba estas funciones en otras provincias, pidieran al Rey Felipe II, en reiteradas ocasiones, que se enviasen representantes jesuitas al país y establecieran en él sus ministerios. ${ }^{4}$

Una vez en Santiago e instalados en su casa, los jesuitas comenzaron su labor docente destinando un día a la semana para que a ella concurrieran los niños a educarse en la doctrina cristiana. Como describe el cronista Miguel de Olivares en su Historia de la Compañía de Jesús en Chile (1593-1736):

"i ellos [los niños] venian con sus cruces mui adornadas cantando las oraciones, donde se les enseñaba $i$ explicaba la doctrina cristiana, i a cantar algunos versos a lo divino para desterrar de sus bocas otras coplas profanas, que corrompen sus costumbres inocentes [sic]". ${ }^{5}$

Así, continúa más adelante el mismo autor: "se enseñaba a los niños de otras escuelas, hasta que en casa pusieron escuela de leer y escribir, donde todos sin tener que pagar maestro, pudiesen acudir a ser enseñados de valde [sic]" ${ }^{6}$

Olivares no puntualiza la fecha exacta en que se produjo la apertura de la cátedra de primeras letras y la de gramática en la casa jesuita, pero, en virtud de lo que él mismo cuenta en la historia que hemos señalado -donde

2 Efectivamente, para el año en cuestión, no existía la instrucción pública institucionalizada en Chile. De hecho, esta fue un área en la vida colonial que se mantuvo por mucho tiempo descuidada, siendo los motivos de esta situación diversos factores que el historiador José Toribio Medina expuso en su texto llamado La instrucción pública en Chile (1905). Para Medina, el tardío y deficiente desarrollo de la instrucción pública en el país se debió a la escasez de habitantes españoles y por consiguiente de familias españolas en los primeros decenios de la conquista; el marcado analfabetismo de los primeros colonizadores; la preocupación constante y casi única por ganarle la guerra a los indígenas del sur, aspecto en el que concentraban casi todas sus fuerzas los primeros habitantes; la carencia absoluta de textos de estudio y de maestros capacitados para enseñar; la incapacidad económica del Cabildo para mantener un maestro de primeras letras, incluso, Medina señala los terremotos, los cuales en más de una ocasión habían destruido los asentamientos completamente, lo que obligó a sus habitantes a concentrarse más en la reconstrucción de los pueblos que en otros temas. Todos estos elementos habrían generado una atmósfera especial en la región, en donde, evidentemente la enseñanza no fue un tema urgente de resolver. José Toribio Medina, La instrucción pública en Chile desde sus orígenes hasta la fundación de la Universidad de San Felipe, (Santiago: Imprenta Elzeviriana, 1905), V-XXXVII.

3 Según los datos proporcionados por José Toribio Medina, en la Catedral de Santiago habría funcionado, desde 1583 aproximadamente, un seminario que fue fundado por el obispo fray Juan Pérez de Espinosa de la Orden franciscana Menor y que fue llamado "Santo Ángel de la Guarda". José Toribio Medina, Ibid., LII.

4 Francisco Enrich, Historia de la Compañía de Jesús en Chile, (Barcelona: Imprenta Francisco Rosal, 1891), 10-11, vol. I.

5 Miguel Olivares, Historia de la Compañía de Jesús en Chile (1593-1736), (Santiago: Imprenta Andrés Bello, 1874), 24.

6 Ibid., 39. 
dice "lo primero que abrieron fue escuela de gramática para que los niños, cuyas capacidades cultivadas no ceden a algunas de otros, más cultos i [sic] políticos reinos, fuesen enseñados e instruidos así en letras como en virtud ",- 7 es probable que esto se haya verificado el mismo año del arribo de los sacerdotes a la ciudad, puesto que, de acuerdo con el testimonio de otro cronista jesuita, el curso de Artes (filosofía), que requería para su aprendizaje del conocimiento de los rudimentos de la lengua latina, habría sido inaugurado el 15 de agosto de $1594 .^{8}$

La apertura del curso de artes en 1594 fue realizada a instancias de la propia comunidad que anhelaba ver a sus jóvenes instruidos en las ciencias mayores, y de los provinciales de las otras órdenes religiosas presentes en Chile, que sentían a sus coristas preparados para aprender filosofía. De esta forma, para asegurarles a los padres de la Compañía un mínimo de asistencia a su lectura, el provincial de Santo Domingo comprometió once de sus religiosos; el de San Francisco, seis; y el de los Mercedarios, otro número que no aparece especificado. También, se contó dentro de sus estudiantes con un grupo de seglares. ${ }^{9}$

Al poco tiempo de establecido el colegio jesuita, específicamente el día 16 de octubre de 1595, el entonces rector de la institución, Luis de Valdivia, recibe una herencia destinada a la fundación de un colegio cuya advocación fue la de San Miguel Arcángel. Con la fundación de este colegio, a fines del siglo XVI, los jesuitas dan comienzo a una exitosa labor educativa en Chile, la cual se propagó por distintas regiones del territorio, gracias a la creación de una serie de instituciones que, replicando el trabajo desarrollado en el Colegio de

\footnotetext{
Ibid., 35.

8 Alonso de Ovalle, Histórica relación del reino de Chile, (Santiago: Instituto de Literatura Chilena, 1969), 539.

A decir verdad, Alonso de Ovalle no establece exactamente que la inauguración de la cátedra de Artes se produjo el año 1594. Esto se infiere por el relato que hace de los acontecimientos, en donde, primero está la construcción del templo jesuita, que se inició en 1593 y que "esperaban verla acabada para el verano siguiente" y luego, "Viendo la ciudad el gran fruto que los nuestros comenzaron a hacer en todos, con deseo de que la juventud participase de el más cumplidamente, rogó a los padres que abriesen las escuelas que acostumbran en otras partes [...]". De todas formas, es preciso señalar que hay confusión entre algunos historiadores respecto del año en que se inauguró esta cátedra, para algunos, como por ejemplo Diego Barros Arana que prologa y anota la Historia de la Compañía de Jesús (1593-1736) del jesuita Olivares, el año es 1593, lo mismo que propone Benjamín Vicuña Mackenna en su Historia crítica y social de la ciudad de Santiago (1869). Para otros, como por ejemplo Francisco Enrich en su Historia de la Compañía de Jesús en Chile (1891) el año es 1594, lo mismo que cree y señala Walter Hanisch en su Historia de la Compañía de Jesús en Chile del año 1974. José Toribio Medina en La Instrucción pública en Chile (1905), es el único, hasta donde alcanzan nuestras lecturas, que no da por sentado el año exacto en que se inauguró esta cátedra, para él no existe claridad en este asunto.

Pese a esto, y de acuerdo con lo que hemos planteado al principio de esta nota, pensamos que es más probable que la inauguración de la cátedra de Artes se haya verificado un año después del arribo de los jesuitas a Chile, pues, es difícil pensar en que esta cátedra, que para ser aprendida requiere de una preparación importante en la lengua latina, haya sido impartida por primera vez al mismo tiempo que la de gramática.

9 De Ovalle, Histórica relación, 539.
} 
San Miguel Arcángel de Santiago, contribuyeron a la formación intelectual de los niños y jóvenes de la época.

\section{Los colegios jesuitas y el régimen que tenían antes de la expul- sión de 1767}

El siglo XVII es un periodo de crecimiento para la Orden ignaciana en territorio chileno. En él, la notoriedad que va adquiriendo en términos de la enseñanza se puede verificar por la aparición de una serie de colegios que, con distinta suerte y en distintos niveles de instrucción, fueron propagando los contenidos que interesaban impartirse en la época.

Así, prosiguiendo con un orden cronológico y retomando la evolución que en estos términos tuvo el Colegio de San Miguel Arcángel de Santiago, nos encontramos que en 1608, cuando el General de la Orden, Claudio Acquaviva, formó la Provincia jesuita del Paraguay -incluyendo en ella el territorio de Paraguay, Tucumán y Chile-, el Provincial Diego de Torres Bollo elevó al rango de Colegio Máximo a la señalada institución, nombramiento que significó que en este colegio se debían implementar las cátedras de las ciencias mayores. Este hecho supuso dos avances importantísimos para la cultura del momento, ya que, además de agregarse a las materias que se impartían las de teología moral y escolástica, se recibieron en Santiago los estudiantes jesuitas de toda la provincia que debían aprender allí filosofía y teología.

Según el historiador jesuita Pedro Lozano, la apertura de la cátedra de teología moral había sido aprobada por el Provincial el año 1608, y su enseñanza estuvo a cargo del Padre Juan Domínguez: “que habiendo leído artes y teología en Lima, aquí prosiguió la lectura con aplauso general y aprovechamiento grande de sus discípulos". ${ }^{10}$ La teología escolástica, por su parte, recién habría sido fundada en 1612, fecha en la que, por otro lado, llegaron a Santiago los profesores y alumnos jesuitas extranjeros que realizaban sus estudios en el Colegio de Córdoba en Tucumán.

El Colegio de Córdoba había sido creado con la intención de convertirse en el máximo de la provincia, pero las dificultades económicas que presentaba la Orden para su manutención obligaron a Diego de Torres a trasladar

10 Citado en Medina, La instrucción pública en Chile, CIXIV. 
los estudios al Colegio de San Miguel en Santiago, el cual, por su parte, se encontraba financieramente más estable. Fue en este contexto que se habilitaron las facultades mayores en el colegio al que hacemos referencia, hecho que, como hemos manifestado, implicó grandes avances para la historia de la instrucción y la vida cultural chilena, puesto que de las enseñanzas que en dichas aulas se impartían, aprendieron, además de los estudiantes jesuitas de toda la provincia, algunos seglares que eran los que estaban internos en el Convictorio Beato Edmundo Campiano ${ }^{11}$ y un grupo de coristas de la Orden mercedaria que luego "sirvieron y lustre y ornamento a su Provincia, y merecieron ocupar los más lúcidos puestos, de que se desempeñaron con crédito y satisfacción". ${ }^{12}$

José Toribio Medina retrata la llegada de los profesores y alumnos a la ciudad de Santiago y señala a los docentes que asumieron la dirección de cada asignatura:

"A la fecha indicada [febrero de 1612] llegaron, pues, á Santiago en compañia del padre Torres, todos los que habian de dar principio al curso de Artes y al de Teología, en unión de sus maestros el padre Manuel de Fonseca, que lo era de teología escolástica, y el padre Francisco Vázquez de la Mota, que habia de leer también teología moral. Venía también el padre Juan de Viana, nombrado rector del Colegio de Santiago. Los recién llegados fueron por todos veinte". ${ }^{13}$

En relación con la forma en la que se enseñaron las materias en este periodo en el Colegio Máximo, esta se ajustó a los lineamientos teórico-prácticos estipulados por la Ratio Studiorum ${ }^{14}$ y, según Enrich, los textos en que basaron sus clases los preceptores fueron, para la cátedra de artes o filosofía, el curso filosófico del Padre Antonio Rubio, que era experto en filosofía aristotélica; para la teología escolástica, los postulados de Francisco Suárez y Gabriel Vázquez y para la teología moral, se empleó a Francisco de Toledo. ${ }^{15}$

11 El Convictorio Beato Edmundo Campiano fue fundado en 1611 por el provincial Diego de Torres Bollo, con el objeto principal de educar en forma integral a los jóvenes de la aristocracia chilena, los cuales, por la ausencia frecuente de sus padres, no recibían una formación constante y adecuada en sus hogares. Este convictorio en 1625 pasó a llamarse San Francisco Javier, porque un decreto papal firmado por Urbano VIII prohibió rendir culto a personas que no estuviesen declaradas como santos por la Santa Sede Apostólica. Edmundo Campiano fue un jesuita mártir nacido en Inglaterra, que había estudiado en uno de los seminarios que tenían los jesuitas en Europa.

Todos los estudios que realizaban los jóvenes internos de este convictorio se hacían en el Colegio Máximo.

12 Ibid., CCI.

13 Ibid., CC-CCI.

14 La Ratio Studiorum es un plan de estudios para los colegios y universidades de la Compañía de Jesús que consiste en un conjunto de reglas para la aplicación de la enseñanza. Su promulgación definitiva fue hecha por el general de la orden Claudio Acquaviva, el año 1599 y mantuvo su vigencia hasta 1773, año en que se suprime definitivamente la Compañía de Jesús.

15 Enrich, Historia de la Compañía, 226, vol. I. 
Es ampliamente conocido el predominio que Suárez tiene para esta Orden, imponiendo su criterio sobre el de Santo Tomás en problemáticas filosóficas tales como la distinción entre esencia y existencia y en su teoría del Estado, que lleva hasta las últimas consecuencias la doctrina de la sumisión del príncipe al bien común. Este último principio, que a grandes rasgos plantea que el poder es dado por Dios a toda comunidad política y no solo a determinados sujetos, fue ampliamente desarrollado por los pensadores jesuitas de fines del XVI y principios del XVII, destacándose entre ellos Juan de Mariana (1536-1624), que llegó a proponer la muerte del soberano a manos del pueblo si este transgredía sus derechos.

Por su parte, el jesuita español Gabriel Vázquez (1549-1604) era seguido en el debate sobre el probabilismo, teoría que consideraba que no era suficiente para no pecar, en casos en los que la aplicación de la regla moral es dudosa, atenerse a una opinión probable (entendiéndose por opinión probable la sostenida por algún teólogo). Esta doctrina fue muy cuestionada por las otras órdenes religiosas, especialmente la dominica, y fue causa de dilatadas impugnaciones por la relajación moral que eventualmente permitía a quienes se adscribían a ella.

Como se puede observar, los jesuitas introducían, por medio de la enseñanza, doctrinas filosóficas que muchas veces reñían con los intereses de la Corona. Tal es el caso, por ejemplo, de lo que hemos comentado sobre los principios que promovía Suárez en sus escritos, los cuales encontraron una fuerte oposición de parte de los gobernantes borbónicos (s. XVIII) y, principalmente, del monarca Carlos III, que fue el que más defendió el regalismo y, por ende, el poder absoluto del monarca en su imperio. No por nada, después de que son expulsados los jesuitas de los territorios españoles en 1767, dictó una Real Cédula (12 de agosto de 1768) en la que prohibía las cátedras de Francisco Suárez y de otros autores y textos que parecían contrarios al sistema que intentaba defender en dicho periodo.

Pero, retornando a la evolución que experimentó el Colegio de San Miguel en 1608, cuando se convirtió en Colegio Máximo, esta no habría sido permanente, pues, en 1614 el provincial decidió trasladar nuevamente los estudios a Córdoba. Este hecho, en contradicción con lo que nos propone 
José Toribio Medina, ${ }^{16}$ no significó que se privara al Colegio Máximo de San Miguel de seguir impartiendo cátedras de artes y teología, pues allí se continuaron educando los jóvenes que reclutaba el Convictorio San Francisco Javier (ex Beato Edmundo Campiano).

Es más, unos años más tarde, cuando Chile se convirtió en Vice-provincia dependiente del Perú (1625), el padre Vice-provincial Juan Romero da cumplimiento a la bula firmada el ocho de agosto de 1621 por el Papa Gregorio $\mathrm{XV}$, en donde se autorizaba a los jesuitas para que en las Islas Filipinas, en Nueva Granada, Tucumán, Río de la Plata, Santiago de Chile, y en las demás provincias y ciudades de Indias en donde no hubiesen estudios generales y distasen más de doscientas millas las universidades públicas, se pudiesen otorgar, con previa aprobación de Obispos o de cabildos eclesiásticos en sede vacante, los grados de bachiller, licenciado, maestro y doctor en facultades de artes y teología. A lo cual, "puso cuanto antes en planta el P. Romero esta facultad; lo que no le sería muy difícil, por enseñarse en él de antemano la filosofía y teología, los cánones y sagradas escrituras, como en todos nuestros colegios máximos se acostumbra". ${ }^{17}$

Así, según refiere el cronista Diego de Rosales, en el colegio jesuita llegaron a funcionar la escuela de niños, dos aulas de gramática, un curso de artes, tres de teología, dos de escolástica y uno de moral, $^{18}$ y a su concurso asistieron estudiantes de todas las ciudades chilenas.

La disposición firmada por el Papa Gregorio XV tenía una vigencia de diez años. El 7 de enero de 1627, Urbano VIII la renueva por diez años más y, el 29 de mayo de 1634, el mismo Papa otorga sin limitación de tiempo el mismo privilegio, en los mismos territorios señalados por la primera disposición.

Señalábamos, al comienzo de este apartado, que el siglo XVII fue un periodo de notable expansión de la Orden jesuita en el territorio chileno, es así como a principios de 1600 el padre Luis de Valdivia regresó de su viaje a España, en donde había tenido que exponer ante la Corte las causas que originaban la insurrección indígena en el sur de Chile y las eventuales soluciones que se podían dar al conflicto. Con el título de Visitador, llega a Concepción el

\footnotetext{
16 El autor sostiene que el traslado de las facultades mayores al Colegio de Córdoba significó que el Colegio de San Miguel quedara solo facultado para impartir las cátedras de primeras letras y gramática. Medina, La instrucción pública en, CCIII.

17 Enrich, Historia de la Compañía de Jesús, 388, vol. I.

18 Diego de Rosales, Historia del reino de Chile: Flandes Indiano (Santiago: Andrés Bello, 1989), 347, tomo I.
} 
13 de mayo de 1612, en compañía de ocho padres jesuitas y dos hermanos coadjutores, a poner en marcha el plan de guerra defensiva, que debía ser implementado para reestablecer la paz en la zona y así poder continuar con la tarea evangelizadora que, producto de los continuos alzamientos, había sido interrumpida.

Tras permanecer un tiempo en la casa del Gobernador Alonso de Rivera, los jesuitas se instalaron en casa propia, la cual fue formalizada como colegio en 1616. Según Olivares, desde el principio de su fundación, este colegio tuvo aula de gramática y escuela de lectura y escritura. ${ }^{19}$ Las ciencias mayores, en tanto, no fueron necesarias hasta más tarde, pues quienes deseaban continuar sus estudios se dirigían al colegio de Santiago.

El día 13 de mayo de 1647 ocurrió en Santiago un terremoto que destruyó por completo la iglesia y el colegio jesuita. Este hecho significó que los estudios que se realizaban en el Colegio Mayor de San Miguel (artes y teología) se trasladasen al de Concepción, mientras que se reconstruía el arruinado edificio. Probablemente, esta experiencia motivó a que los jesuitas de Concepción quisiesen iniciar el curso de artes en el colegio, puesto que, cuando retornan los estudios a Santiago, esta cátedra habría continuado enseñándose ocasionalmente hasta el año 1724, que es cuando la comienzan a impartir regularmente en el Colegio Seminario de San José.

El Colegio Seminario San José fue fundado por el Obispo de Concepción Juan Nicolalde (1716-1724), el año 1718. Este, ante la escasez de personas idóneas que pudieran encargarse de la dirección del establecimiento y, en vista de la reputación que los padres de la Compañía poseían en todo lo concerniente a la enseñanza, les encargó a ellos que se ocupasen del Colegio Seminario. Los jesuitas aceptaron la demanda y en 1724 asumieron su dirección, dando con ello inicio a la enseñanza de la filosofía, la teología escolástica, dogmática y moral, en Concepción.

Amparados en la misma bula firmada por el Papa Gregorio XV en 1621, y ratificada luego por el papa Urbano VIII en 1634, los jesuitas comenzaron a otorgar grados académicos de bachillerato, maestro y doctor en artes y teología en dicho colegio, en virtud de lo cual, la institución se convirtió

19 Olivares, Historia de la Compañía de Jesús en Chile, 223. 
en universidad y adoptó el nombre de Universitas Pencopolitana, Reales et Pontificia o Universidad Pencopolitana. ${ }^{20}$

El aporte que en términos de la cultura significó esta universidad es notable, pues, como advierte el historiador Fernando Campos Harriet, de sus aulas "se graduaron alumnos esclarecidos como don Alonso de Guzmán y Peralta, prestigioso jurista; el Dr. Manuel Alday y Aspée, después célebre Obispo de Santiago; Arturo Rodríguez Venegas, gran benefactor del Convento de las Trinitarias $[\ldots]^{\prime \prime 21} \mathrm{e}$, incluso, hay antecedentes de que el eminente naturalista Juan Ignacio de Molina, también pasó por sus aulas. ${ }^{22}$

La oportunidad que tuvieron los jesuitas de hacerse cargo de la promoción de los grados académicos que se otorgaban en las universidades pontificias se debió, principalmente, al prestigio que había adquirido la pedagogía ignaciana durante el siglo XVII, prestigio que, por otro lado, daba cuenta del alto grado de organización y efectividad que poseía esta enseñanza.

Llegados a este punto, es preciso repasar el fundamento que tiene para la Orden ignaciana la enseñanza, puesto que en ellos se descubre el origen del sistema educativo que se siguió indistintamente en todos los colegios que tuvo la orden. Según se desprende de la cuarta parte principal de las Constituciones de la Compañía de Jesús (1558), que fue escrita por su fundador, San Ignacio de Loyola, la enseñanza es concebida como el cultivo simultáneo de la virtud moral y el intelecto, es decir, que se entiende que para que el individuo mejore en la instrucción, debe mejorar en el temor a Dios y en todas las virtudes que encaminan al hombre a su fin último que es la vida eterna, sin esta simultaneidad, la formación intelectual se considera vana y peligrosa. En este sentido, el fin de la pedagogía ignaciana es apostólica y teologal, puesto que su intención es ayudar a las almas para alcanzar su perfección y encaminar al hombre hacia conocimiento de la gloria divina y, después de que esto se ha alcanzado, "será de procurar el edificio de las letras y el modo de usar de ellas, para ayudar a más conocer y servir a Dios nuestro Criador y Señor". ${ }^{23}$

20 La Universidad funcionó ininterrumpidamente hasta que el terremoto y maremoto, ocurridos en Concepción el año 1751, destruyeron por completo sus dependencias.

21 Fernando Campos Harriet, Historia de Concepción 1550-1970 (Santiago: Editorial Universitaria, 1980), 115.

22 Ibid.

23 San Ignacio de Loyola, “Constituciones de la Compañía de Jesús”, en Obras, eds. Ignacio Iparraguirre y Cándido de Dalmases (Madrid: BAC, 1997), 531. 
Es así como en los colegios jesuitas los estudios siempre se deben ordenar al bien del alma y del prójimo y, según esta medida -dice San Ignacio- se determinarán en universales y en particulares las materias que deben integrar el plan de estudio. ${ }^{24}$ En correspondencia con lo anterior, en la Ratio Studiorum, que, como dijimos en otro lugar, fue el plan de estudios de la Compañía de Jesús, los contenidos son ordenados en dos grandes ciclos que parten desde el conocimiento más básico que debe tener el educando, hasta llegar al más complejo. En el primero de ellos, el de "estudios inferiores", que se desarrolla en cinco años, se destinan tres a la gramática (elemental, media y superior) de la lengua latina, griega y hebrea; uno, a humanidades y otro para retórica.

Luego vienen el segundo y tercer ciclo, que corresponden a los "estudios superiores". Estos, se organizan de la siguiente manera, el segundo ciclo está reservado al currículum de filosofía. La filosofía se pasa en tres años, dentro de los cuales uno se destina a la lógica y matemática; otro, a la física y a la ética; y, el último, a la metafísica, psicología y matemática superior. El tercer ciclo, que contempla el estudio de teología, se cursaba durante cuatro años y estaba destinado a quienes querían continuar la carrera sacerdotal.

La teología era el conocimiento más importante para el plan jesuita, por lo mismo, ocupa el último lugar en esta suerte de progresión gnoseológica, que parte de lo más elemental a lo más complejo. Este hecho es completamente comprensible dado el contexto en que se desarrolla la enseñanza jesuita y la orientación que inicialmente se planteó la Orden cuando asumió este ministerio. No hay que perder de vista que el fin con que la Compañía de Jesús emprendió la función educativa fue la preparación de jóvenes que querían seguir la carrera sacerdotal en la Orden. Que luego las puertas de sus colegios se hayan abierto al resto de la comunidad, no quita que el sentido original que se trazó esta pedagogía haya permanecido.

En el segundo lugar, en el nivel de complejidad y relevancia, se encuentran los estudios de la filosofía, el cual parte desde el conocimiento de las verdades empíricas, es decir de la física, hasta las más abstractas y trascendentales como son las matemática y la metafísica. Es preciso que para llegar a este grado de complejidad en los estudios, los alumnos posean un conocimiento acabado del latín y del griego, pues los textos en que basan sus aprendizajes

24 Ibid., 541. 
están escritos en estas lenguas. Desde ahí se comprenden los cinco años que se destinan a la gramática de estas lenguas en los estudios inferiores.

Las doctrinas enseñadas en todos los estudios deben ser las más seguras y aprobadas, según el uso universal de la Compañía, no debiéndose aceptar ideas nuevas en cualquiera de las ciencias que se enseñan. Es así como San Ignacio de Loyola deja propuesto a los autores más adecuados que habrían de seguirse en las cátedras jesuitas y, en caso de dejar a elección del Rector, el autor a emplear deja trazado el criterio con que este debe ser seleccionado. Por ejemplo, para la facultad de Humanidades propone seguir en gramática a Manuel Álvarez; en retórica y poética latina, sugiere a Quintiliano, Cicerón y Virgilio y, en griego, a Demóstenes, Crisóstomo y San Jerónimo. Si la elección depende del Rector del establecimiento, "escúsese [sic] [...] cuanto será posible, de leer a la juventud ninguno en que haya cosas que ofendan las buenas costumbres, si no son primero limpiados de cosas y palabras deshonestas". 25

En la facultad de Artes o Filosofía (lógica, física, metafísica, moral y matemática), se recomienda seguir a Aristóteles y Santo Tomás, dándose libertad para incorporar a otros autores en los puntos en que los señalados no se expresan. En los estudios teológicos, se recomienda a Santo Tomás y Pedro Lombardo y, finalmente, cuando el alumno tiene un dominio en el fundamento escolástico, se comienza el estudio de las Sagradas Escrituras. En cuanto al derecho, se enseñaba algo de derecho canónico en relación con la teología moral, mientras que la medicina no fue nunca habilitada en las universidades jesuitas chilenas.

Como en la tradición escolástica medieval, las clases consistían en la lectura comentada de un autor y en la posterior repetición de los principios más relevantes que se habían enseñado en la lectura. Este método suponía un gran esfuerzo intelectual y memorístico de parte del educando, pues, al ser la lectura completamente oral, sin soporte escrito alguno, el estudiante estaba obligado a poner la mayor atención posible a lo que explicaba el preceptor, ya que si no lo hacía, corría el riesgo de equivocarse en la repetición y recibir a cambio una amonestación del maestro, la cual por lo general consistía en un azote.

25 Ibid., 562. 
Este mecanismo de enseñanza fue muy efectivo, en el sentido de asegurar los contenidos que el alumno debía aprender, ya que, al ser esencialmente memorístico, limitaba cualquier reflexión personal que pudiese poner en cuestionamiento el principio que al maestro le interesaba imprimir en la memoria de sus educandos.

El tercer momento didáctico que se puede reconocer en la pedagogía ignaciana, es la aplicación, que consistía en el ejercicio práctico de los conocimientos adquiridos por los estudiantes. Según la asignatura, la aplicación podía desarrollarse como composiciones escritas, como era la forma desarrollada en los cursos de retórica y literatura o, como disputas, que era la ejercitada por los estudiantes de filosofía y teología.

En las disputas, que se hacían semanalmente y en público, el alumno proponía una tesis a partir de los textos estudiados en clases y la defendía de las argumentaciones contrarias que eventualmente suscitaba en quienes participaban del evento. Un moderador, que por lo general era el docente, regulaba el debate.

Respecto a los grados que eran entregados en las universidades jesuitas, el historiador Mario Góngora plantea que estos se conferían siguiendo las Ordenanzas que fueron dictadas por el P. Pedro de Oñate para la Universidad de Córdoba. ${ }^{26}$ Así, el bachillerato en artes se obtenía al final del segundo año, y su examen de obtención versaba sobre lógica. La licenciatura, por su parte, se entregaba a mediados del tercer año y su examen consistía en defender doce conclusiones, tomadas tres de lógica, tres de física, tres de generación, corrupción y de ánima, y tres de metafísica. El grado de maestro en artes requería, además del curso de tres años, medio año más con pasante y su examen duraba una hora y media, sobre toda la filosofía, sin conclusiones.

El bachillerato de teología tenía que serlo ya en artes o en sus efectos, se debía probar la asistencia a los cursos de aquel ramo durante un periodo de cuatro años. En su examen se defendían nueve conclusiones. El aspirante a licenciado estaba obligado a seguir dos años con un pasante y rendir una serie de pruebas. Finalmente, el doctorado en teología exigía que después de la licenciatura se estuviese un año con pasante y su examen, que duraba cinco

26 Mario Góngora, "Notas para la historia de la educación universitaria colonial de Chile", Anuario de Estudios Americanos. Tomo VI. (1949): 191. 
horas consistía en una hora de puntos en Santo Tomás y cuatro horas para defender doce conclusiones sobre toda la teología. El doctor recibía el título una vez que prestaba juramento de exaltar la Inmaculada Concepción, de obedecer a la Iglesia, al Romano Pontífice y al Rey, además de comprometerse a auxiliar a la Universidad en sus actos y consejos. ${ }^{27}$

\section{CONCLUSIÓN}

Este esquema general que hemos esbozado es el que se seguía en todos los colegios jesuitas, incluidos los de Chile. Como en este país, hacia el tiempo en que llegan jesuitas solo existían actividades educativas aisladas que no llegaron a constituirse en un sistema general de enseñanza, podemos establecer, a modo de conclusión, que con la implementación de la pedagogía ignaciana se estableció, por primera vez en Chile, un sistema general que contribuyó al desarrollo de una educación más organizada en el país, siendo este aspecto el que hemos querido destacar en este trabajo y para lo cual hemos señalado sus características generales.

\section{FUENTES}

De Loyola, San Ignacio. “Constituciones de la Compañía de Jesús”. En Obras, editado por Ignacio Iparraguirre y Cándido de Dalmases, 431-646. Madrid: BAC, 1997.

De Olivares, Miguel. Historia de la Compañía de Jesús en Chile (1593-1736). Santiago: Imprenta Andrés Bello, 1874.

Enrich, Francisco. Historia de la Compañía de Jesús en Chile. Vol. I. Barcelona: Imprenta Francisco Rosal, 1891.

\section{REFERENCIAS}

De Rosales, Diego. Historia del reino de Chile: Flandes Indiano. Santiago: Andrés Bello, 1989. Tomo I.

Góngora, Mario. "Notas para la historia de la educación universitaria colonial de Chile". Anuario de Estudios Americanos, Tomo VI (1949): 163-229.

27 Ibid., 189. 
Medina, José. La instrucción pública en Chile desde sus orígenes hasta la fundación de la Universidad de San Felipe. Santiago: Imprenta Elzeviriana, 1905.

Contreras Gutiérrez, Alejandra, “La enseñanza Jesuita en Chile colonial: Sus colegios, universidades y una aproximación a sus métodos y contenidos". Revista Historia de la Educación Latinoamericana. Vol. 16 No, 22, (2014):
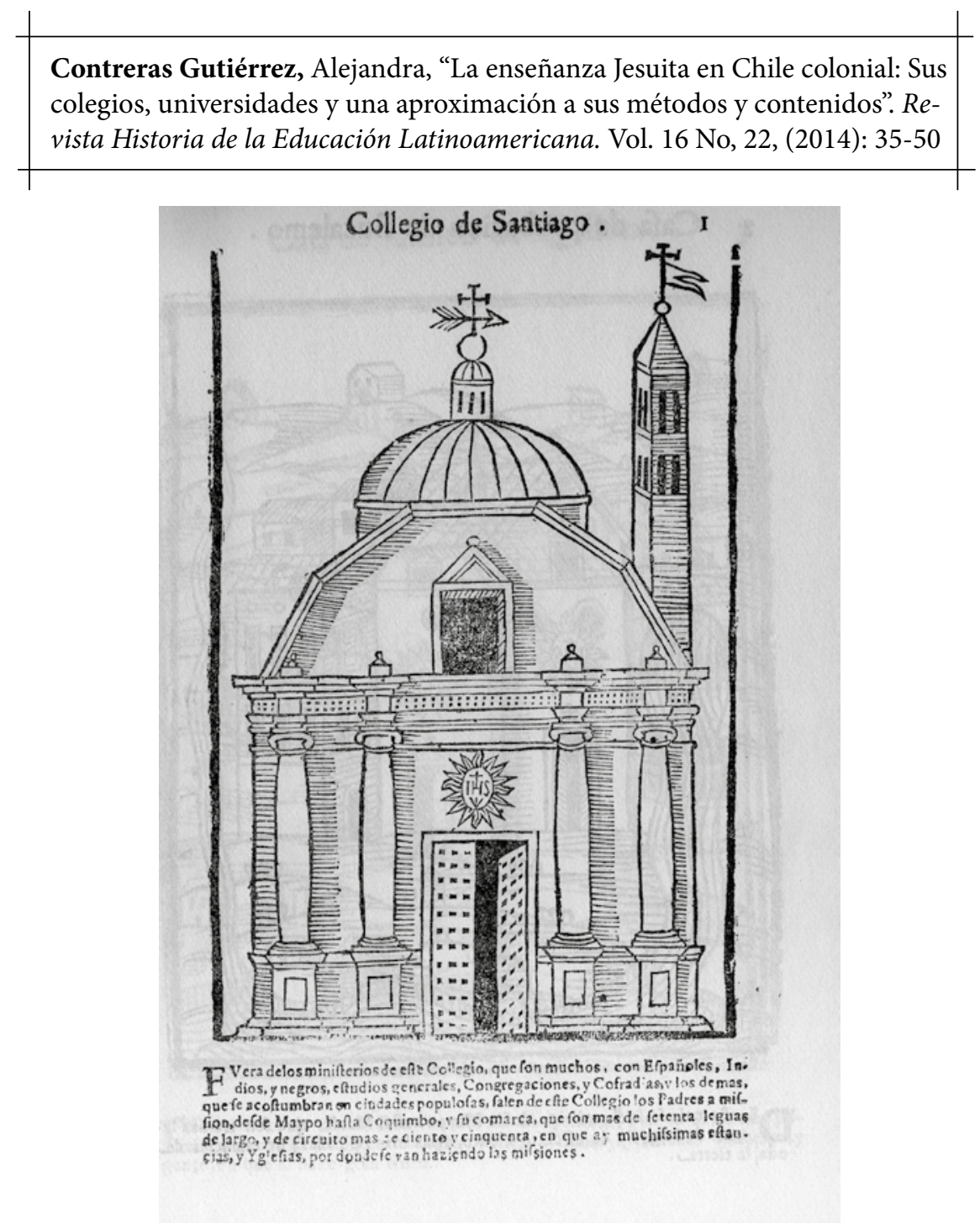